American Journal of Pharmacology and Toxicology 1 (1): 5-10, 2006

ISSN 1557-4962

(c) 2006 Science Publications

\title{
Effects of Administration of Alpha-Melanocyte Stimulating Hormone ( $\alpha$-MSH) on Some Hematological Values of Alloxan-induced Diabetic Rats
}

\author{
Kamal Mohmoud Saleh Mansi \\ Department of Biological Sciences, Al al-Bayt University, Al-Mafraq, Jordan
}

\begin{abstract}
This study was designed to evaluate the role of alpha- melanocyte stimulating hormone ( $\alpha$ $\mathrm{MSH}$ ) on heart rate and some hematological values in alloxan induced diabetic rats. 40 male white rats were divided into four experimental groups: control, diabetic, $\alpha$-MSH-treated and $\alpha-\mathrm{MSH}$-treated diabetic. At the end of the experimental period (3weeks), animals in all four groups were fasted for 12 hrs and blood samples were taken for the determination of plasma insulin, Glucagon, glucose levels, RBC and WBC (red and white blood cell) counts, packed cell volume (PCV), erythrocyte sedimentation rate $(\mathrm{ESR})$ and hemoglobin $(\mathrm{Hb})$ concentration. It was found that $(\alpha-\mathrm{MSH})$ increased the lowered RBC and WBC counts, PCV and neutrophil percentage in diabetic rats. However the WBC counts of the $(\alpha-\mathrm{MSH})$ treated diabetic group was still lower than the control and $(\alpha-\mathrm{MSH})$ group. $(\alpha-$ MSH) also decreased the elevated heart rate, ESR and glucose concentration of diabetic rats. The hormone was investigated for hypoglycemic effect in diabetic rats and induced not significant reduction in serum glucose from $(19.83 \pm 1.25 \mathrm{MmolL})$ in diabetic group to $(15.7 \pm 1.10 \mathrm{MmolL})$ in $(\alpha-$ MSH)-treated diabetic group. However the blood glucose still higher than the control and ( $\alpha-\mathrm{MSH})$ group, serum insulin increased from $\left(0.55 \pm 0.08 \mathrm{ng} \mathrm{mL}^{-1}\right)$ in control group to $\left(0.65 \pm 0.06 \mathrm{ng} \mathrm{mL}^{-1}\right)$ in $\alpha$ $\mathrm{MSH}$-treated group and still higher than control in $\alpha$-MSH-treated diabetic $\left(0.59 \pm 042 \mathrm{ng} \mathrm{mL}^{-1}\right)$ and serum Glucagon increased in diabetic, $\alpha$-MSH-treated and $\alpha-\mathrm{MSH}$-treated diabetic groups.

It is concluded that treatment $(\alpha-\mathrm{MSH})$ might decrease the diabetes-induced disturbances of heart rate and some hematological parameters of alloxan-induced diabetic rats.
\end{abstract}

Key words: Alpha-MSH, alloxan, hypoglycemic agents, insulin, heart rate, hematological values

\section{INTRODUCTION}

Diabetes Mellitus (DM) represents a heterogeneous group of disorders that have hyperglycemia as a common feature ${ }^{[1,2]}$. Al though Diabetes has long been considered a disease of minor significance, it is considered now as one of the main threats to human health in 21 st century. Great changes in the human environment, behavior and lifestyle resulted in the raising rates of Diabetes ${ }^{[3]}$. (DM) is consequence of defects in secretion, insulin action or both, which is translated into abnormalities of carbohydrate, fat and protein metabolism resulting in hyperglycemia ${ }^{[4,5]}$. Symptoms of chronic hyperglycemia include polyuria, polydipsia and polyphagia as well as weight loss. Although varying among patients, long term complications of Diabetes can also include changes in arteries (arteriosclerosis), basement membranes of small vessels (microangiopathy), (kidneys (nephropathy), retina (retinopathy) and nerves (neuropathy ${ }^{[6-8]}$. DM leads to many complications, such as increasing the risk of developing arterial disease by two to six folds ${ }^{[9]}$. It has been suggested that the heart rate is higher, red and white blood cells counts lower in type diabetes than in non-diabetic ${ }^{[10,11]}$. There is some evidence that diabetics present a deficiency in mounting an inflammatory response, probably associated with severe reduction in insulin secretion rather than increased blood glucose levels ${ }^{[1,2,13]}$. This is still a controversial point as other investigators have suggested a direct correlation between hyperglycemia and the incidence of infection in diabetic patients ${ }^{[14]}$.

Alpha-melanocyte-stimulating hormone (Alpha $\mathrm{MSH}$ ) is a tridecapiptide that was originally characterized a neuropeptide derived from a pituitary $\alpha$ MSH is hormone derived by post-translational processing from POMC and involved in stress and background adaptation. Alpha-MSH is synthesized from pro-opiomelanocortin (POMC) by the action of specific prohormone convertases that cleave into $\alpha$ MSH, ACTH and Beta-endorphin. Alpha-MSH seems to be modulated by the release of two hormones within the hypothalamus: melanoncyte stimulating hormone releasing factor (MSHRF) and melanocyte stimulating hormone release-inhibiting factor (MSH-RIF).

Five G-protein-coupled melanocortin receptors (MC (1)-MC (5)) are expressed in mammalian tissues. The melanocortin receptors support diverse physiological functions, including the regulation of hair color, adrenal function, energy homeostasis, feed efficiency, sebaceous gland lipid production and immune and sexual function. The hormone is a

Corresponding Author: $\quad$ Kamal Mohmoud Saleh Mansi, Department of Biological Sciences, Al al-Bayt University, AlMafraq, Jordan, Telfax: 0096265151261, Mob.: 00962777357681 
neuroimmunomodulating peptide that was recently detected in many none pituitary tissues including the skin, Accordingly, epidermal cells such as keratinocytes and melanocytes (as well as dermal cells such as fibroblasts and endothelial cells). Neuropeptide AlphaMelanocyte stimulating hormone is known to suppress cytokine, suppressed the production of the proinflammatory cytokine interferon (IFN)- mediated gamma by antigen stimulated primed lymph node $\mathrm{T}$ cell $^{[15]}$.

More finding indicates that $\alpha$ - MSH is part of the mediator network that regulates cutaneus inflammation and hyperproliferation skin diseases ${ }^{[16]}$.

$\alpha-\mathrm{MSH}$ is known to have pleitrophic functions including pigmentary, anti-inflammatory, antipyretic and immunoregulatory roles in the mammalian body as reduction nterleukin-1 beta effects on rat stomach ${ }^{[17]}$, inhibits lipolyscchride-induced biological responses by down regulating CD14 from macrophage, suppresses antigen-stimulated T-cell production ${ }^{[18]}$. It is also reported to more influences, as treatment of various skin disorders including inflammatory dermatoses ${ }^{[19]}$, modulates local and circulating tumor necrosis factor (TNF) in experimental brain inflammation ${ }^{[20]}$, this hormone can inhibit the induction of contact hypersensitivity reactions and to induce hapten-specific tolerance $^{[21]}$, anti-inflammatory and anti-invasive effects in human melanoma cells ${ }^{[22]}$, the antiinflammatory actions of the peptide via peripheral and /or central melanocortin receptors might put the peptide into practice therapeutically in near future ${ }^{[23]}$.

More studies suggest that $\alpha$ - MSH, decrease body fat in humans ${ }^{[2]}$ as a potential neurotransmitter ${ }^{[25]}$, regulate energy balance, appetite control, as well as glucose transport in rat adipocytes ${ }^{[26]}$.

\section{MATERIALS AND METHODS}

Animals: White laboratory male rats (150-200 g) six to eight weeks of age were housed in cages under standard laboratory conditions for at least $1 \mathrm{wk}$ before starting the experiments. 40 white male rats were divided equally into four experimental groups (control, diabetic, $\alpha$ - MSH treated and $\alpha$ - MSH treated diabetic).

The control group was injected with physiological saline. The second group was made diabetic by interaperitoneal injections of $10 \%$ alloxan (Sigma chemical Co., St Louis, Mo, USA) dissolved in physiological saline to induce diabetes (150 mg Kg body weight). Three days after alloxan injection diabetes was confirmed by the demonstration of hyperglycemia (Blood glucose $\geq 300 \mathrm{mg} \mathrm{dL}^{-1}$ ), rats with marked hyperglycemia (FBS $>250 \mathrm{mg} \mathrm{dL}^{-1}$ ) were selected and used for the study.

The diabetic- $\alpha$ - MSH -treated group was injected intramuscularly with $\alpha$ - MSH (sigma Formula) $2 \mathrm{mg}$ $100 \mathrm{~g}^{-1}$ of body mass daily for three weeks after the induction of diabetes.
Haematological analysis: At the end of the experimental period ( 3 weeks) the animals in all groups were fasted for $12 \mathrm{hrs}$ and blood samples were taken to determine glucose levels, RBC, WBC counts, packed cell volume (PCV), erythrocyte sedimentation rate (ESR) and haemoglobin (Hb) concentration. Serum glucose concentration was measured immediately. PCV, RBC, WBC and haemoglobin were determined, erythrocyte sedimentation rate (ESR) determined by Westengren method, differential WBC count was performed on Geimsa stained blood smears. Heart rate was measured by electrocardiograph before blood withdrawal.

Insulin determination: Serum Insulin was measured by radioimmunoassay methods (CEA-JRE-SORIN Firm, France).

\section{RESULTS AND DISCUSSION}

The results obtained showed that, serum glucose increased significantly (17.1 $\pm 1.2 \mathrm{MmolL})$ compared to control group $(5.7 \pm 0.25)(\mathrm{p}<0.05)$ (Table 1). Serum insulin decreased significantly $\left(0.38 \pm 0.08 \mathrm{ng} \mathrm{mL} \mathrm{mL}^{-1}\right)$ compared to control $\left(0.54 \pm 0.22 \mathrm{ng} \mathrm{mL}^{-1}\right)(\mathrm{p}<0.05), 72$ hrs after alloxan administration. As shown in Insulin level decreased in diabetic rats $\left(0.38 \pm 0.08 \mathrm{ng} \mathrm{mL}^{-1}\right)$ and still higher than control in $\alpha$-MSH-treated diabetic $\left(0.59 \pm 042 \mathrm{ng} \mathrm{mL} \mathrm{m}^{-1}\right)(\mathrm{p}<0.05)$ (Table 3) and serum Glucagon increased in diabetic $\left(64 \pm 0.58 \mathrm{pg} \mathrm{mol}^{-1}\right)(\mathrm{p}<$ $0.05), \alpha$-MSH-treated $\left(38 \pm 0.40 \mathrm{pg} \mathrm{mol}^{-1}\right)$ and $\alpha-\mathrm{MSH}-$ treated diabetic groups $\left(58 \pm 0.21 \mathrm{pg} \mathrm{mol}^{-1}\right)(\mathrm{p}<0.05)$ compared to control $\left(32 \pm 2.23 \mathrm{pg} \mathrm{mol}^{-1}\right)$.

During the experimental period we studied the symptomic complex of features in development of DM in rats after administration of alloxan, such as changes in appearance of an animal, the body weight and volume of water drunk, volume of urine excreted and determination of protein, ketones and serum glucose (Table 1) and the animals showed the following symptoms Polydipsia, polyuria, weight loss, weakness and dehydration.

It was found that the RBC and WBC count, PCV, ESR and neutrophil percentage was decreased $(\mathrm{P}<$ 0.05). Moreover neutrophils from diabetics have also been shown to present functional abnormalities such as less phagocytizing capacity and chemotactic responses ${ }^{[27]}$. Which might be extended to other inflammatory cells as those involved in allergic processes and the heart rate increased $(\mathrm{P}<0.05)$ in diabetic rats (Table 2).

Alloxan induces damage and death of pancreatic islet-cells in several experimental animal models, thus causing diabetes mellitus and decreasing the secretion of insulin. The cytotoxic action of this diabetogenic agent is mediated by reactive oxygen species, Alloxan and the product of its reduction, dial uric acid; establish a redox cycle with the formation of super oxide 
Am. J. Pharm. \& Toxicol., 1 (1): 5-10, 2006

Table 1: Characteristics of rats after injection. Plasma glucose concentration of normal control, uncontrolled diabetic and $\alpha$-MSH - treated diabetic rats, expressed as mean \pm SEM

\begin{tabular}{|c|c|c|c|c|}
\hline Characteristic & Control & $* \alpha$-MSH - treated & Diabetic & $\alpha$-MSH - treated diabetic \\
\hline Body weight (g) & $186 \pm 9.88$ & $198 \pm 10.88$ & $178 \pm 13.0$ & $177.6 \pm 6.3$ \\
\hline Water drunk mL day ${ }^{-1}$ & $9.4 \pm 1.64$ & $12.6 \pm 0.65$ & $23.33 \pm 4.40$ & $15.3 \pm 3.01$ \\
\hline Urine excreted $\mathrm{mL}$ day $^{-1}$ & $4.8 \pm 0.42$ & $8.6 \pm 0.83$ & $11.30 \pm 1.26$ & $9.42 \pm 0.42$ \\
\hline Protein (urine) & - & + & ++ & + \\
\hline Ketone (urine) & - & + & ++ & + \\
\hline Glucose (urine) & - & - & +++ & + \\
\hline \multicolumn{5}{|l|}{ Blood glucose } \\
\hline MmolL & $5.7 \pm 0.25$ & $12 \pm 0.35$ & $17.1 \pm 1.25$ & $14 \pm 1.10$ \\
\hline
\end{tabular}

* $\alpha$-MSH - treated rates

component is absent; + component is present in small amount; ++ component exists in large amount; +++ component exists in the largest level.

Table 2: Comparative hematological values and heart rates of normal control, uncontrolled diabetic and N.S-treated diabetic rats, expressed as mean \pm SEM

\begin{tabular}{|c|c|c|c|c|}
\hline Parameters & Control & $\alpha$-MSH-Treated & Diabetic & $\alpha$-MSH- treated diabetic \\
\hline $\mathrm{RBC}\left(\mathrm{x} 10^{6} \mu \mathrm{L}^{-1}\right.$ & $5.6 \pm 0.3$ & $5.9 \pm 0.7$ & $4.2 \pm 0.2$ & $4.9 \pm 0.5$ \\
\hline $\mathrm{WBC}\left(\mathrm{x} 10^{3} \mu \mathrm{L}^{-1}\right.$ & $5.4 \pm 0.6$ & $4.8 \pm 0.4$ & $3.7 \pm 0.26$ & $3.6 \pm 0.38$ \\
\hline $\mathrm{Hb}\left(\mathrm{g} \mathrm{dL}^{-1}\right)$ & $12 \pm 0.9$ & $12 \pm 0.8$ & $12 \pm 1.2$ & $12 \pm 1.1$ \\
\hline $\operatorname{ESR}\left(\mathrm{mm} \mathrm{h}^{-1}\right)$ & $14 \pm 2.3$ & $12 \pm 1.8$ & $20 \pm 2.4$ & $17 \pm 1.6$ \\
\hline Neutrophils\% & $32 \pm 3.7$ & $36 \pm 3.9$ & $24 \pm 3.2$ & $36 \pm 3.4$ \\
\hline Basophiles\% & $2 \pm 0.2$ & $2 \pm 0.9$ & $3 \pm 0.6$ & $3 \pm 0.3$ \\
\hline Eosinophils & $3 \pm 0.2$ & $4 \pm 0.6$ & $4 \pm 0.5$ & $4 \pm 0.4$ \\
\hline Lymphocytes\% & $61 \pm 3.6$ & $64 \pm 4.2$ & $63 \pm 4.1$ & $58 \pm 3.7$ \\
\hline Monocytes\% & $4 \pm 0.4$ & $6 \pm 0.8$ & $6 \pm 0.3$ & $3 \pm 0.3$ \\
\hline PCV\% & $37 \pm 2.6$ & $38 \pm 1.9$ & $30 \pm 2.3$ & $35 \pm 2.6$ \\
\hline Heart rate $\left(\right.$ Beats $\left.\min ^{-1}\right)$ & $359 \pm 11$ & $342 \pm 21$ & $272 \pm 25$ & $298 \pm 17$ \\
\hline
\end{tabular}

Table 3: Plasma hormone concentrations of normal control, uncontrolled diabetic, $\alpha$-MSH - treated and $\alpha$-MSH -treated diabetic rats

\begin{tabular}{|c|c|c|c|c|}
\hline Hormone & Control & $\alpha-\mathrm{MSH}-$ treated & Diabetic & $\alpha$-MSH -treated diabetic \\
\hline Insulin $\left(\mathrm{ng} \mathrm{mL} L^{-1}\right)$ & $0.54 \pm 0.22$ & $0.65 \pm 1.2$ & $0.38 \pm 0.08$ & $0.58 \pm 0.06$ \\
\hline Glucagon $\left(\mathrm{pg} \mathrm{mol}^{-1}\right)$ & $32 \pm 2.23$ & $38 \pm 0.40$ & $64 \pm 0.58$ & $58 \pm 0.21$ \\
\hline
\end{tabular}

radicals. These radicals undergo dismutation to hydrogen peroxide. Thereafter highly reactive hydroxyl radicals are formed by the Fenton reaction. The action of reactive oxygen species with a simultaneous massive increase in cytosolic calcium concentration causes rapid destruction of ß-cells.

Intramuscularly injection of 25 micrograms alphamelanocyte stimulating hormone (alpha-MSH) cased plasma levels of insulin to increase $\left(0.65 \pm 1.2 \mathrm{ng} \mathrm{mL}^{-1}\right)$ but increased insulin resistant (cells in the body are not using the insulin produced by pancreas well enough. while the beta cells in the pancreas are producing adequate levels of insulin), plasma levels of glucose were not significant decreased by 25 micrograms alphaMSH in fed rats. The mechanism by which alpha-MSH increased the plasma levels of glucagons $(38 \pm 0.40 \mathrm{pg}$ $\mathrm{mol}^{-1}$ ) and insulin in rats remains to be determined. It is possible, that the effects were mediated by both a central nervous action and a direct action on the endocrine pancreas. It was suggested that administration of $\alpha$ - MSH to mice or rabbits Increased plasma levels of glucagon, free fatty acids and increased resistance to insulin and directly affected blood sugar levels, therefore, $\alpha$ - MSH may be a factor in the development of Type 2 Diabetes. Another findings show that obese people with high levels of the hormone $\alpha$ - MSH may be more likely to be diabetic than obese people with low levels of the hormone $\alpha$ -
MSH and it was suggested that the mice didn't induce any glucagon in the absence of $\alpha-\mathrm{MSH}$ and will be hypersensitivity to insulin. It has been suggest that Melanonortin 5 receptor was detected in rat adipocytes by RT-PCR. Nle4, D-Phe7- $\alpha$-MSH did not affect the based glucose transport but reduced the insulinstimulated glucose transport in adipocytes in a dosedependent manner. About $45 \%$ of inhibition was observed with $1 \mathrm{nM}$ Nle4, D-Phe7- $\alpha$-MSH under insulin stimulation. Nle4, D-Phe7- $\alpha$-MSH did not affect the insulin-stimulated translocation of GLUT4 from the intracellular pool to the plasma membrane ${ }^{[28]}$ and some results suggest that the beta-endorphininduced hyperglycemia was caused, at least in part, by a peripheral inhibition of insulin release and a central stimulation on glucoregulation.

It was also found that the RBC and $\mathrm{WBC}$ counts, PCV and neutrophil percentage decreased $(\mathrm{P}<0.05)$ and the heart rate increased $(\mathrm{P}<0.05)$ in diabetic rats.

It was suggested that Patients with diabetes mellitus often have autonomic dysfunction and their reduced ability to regulate heart rate (HR) is attributed to an impairment of cardiac and/or central parasympathetic function. The diabetic injury to the parasympathetic nervous system may reduce heart rate variability (HRV), which is predominantly determined by parasympathetic control and is a valuable index of cardiac parasympathetic nerve functional integrity ${ }^{[29]}$. 
Although extensive clinical investigations on cardiac autonomic neuropathy in diabetic patients have been performed, scanty information is available on whether chronic experimental diabetes is associated with cardiac parasympathetic nerve abnormalities

The roopiomelanocortin (POMC)-derived tridecapeptide $\alpha-\mathrm{MSH}$ is a neuropeptide involved in a variety of biological processes, such as pigmentation (30, body weight regulation ${ }^{[31]}$ and inflammation ${ }^{[32,33]}$. It is now well established that $\alpha$ - MSH participates in the regulation of immune responses by impairing important functions of both antigen-presenting cells as well as $\mathrm{T}$ cells ${ }^{[21]}$ and several lines of evidence in POMC peptides such as $\alpha$ - MSH exert their biological activities through the activation of a family of five different $G$ protein-coupled melanocortin receptors (MC-Rs). The MC-1R, which is capable of binding $\alpha$ MSH with high affinity in humans and rodents, is expressed on immune cells such as monocytes, macrophage cell lines, dendritic cells and neutrophils. Many of the anti-inflammatory indicate that $\alpha$-MSH has a variety of anti-inflammatory activities ${ }^{[35-40]}$. Immunomodulatory activities of $\alpha$ - MSH such as suppression of fever induced by IL-1 or IL-6, induction of the anti-inflammatory mediator IL-10, or inhibition of macrophage functions and leukocyte migration are mediated by the activation of this MC- $\mathrm{R}^{[41-43]}$.

Our study indicated that $\alpha-$ MSH treatment increased $(\mathrm{P}<0.05)$ the lowered $\mathrm{RBC}$ and $\mathrm{WBC}$ counts, $\mathrm{PCV}$, ESR and neutrophil percentage in diabetic rats. However, the WBC count of the $\alpha-\mathrm{MSH}$ - treated diabetic group was still lower than those of control values. $\alpha$ - MSH treatment also decreased the elevated heart rate of diabetic rats to normal level (Table 2)

The present study indicated that $\alpha-$ MSH. Treatment might ameliorate some disturbed hematological parameters of diabetic rats. It has been suggested that anemia occurrence in DM is due to the increased non-enzymatic glycosylation of RBC membrane proteins, which correlates with hyperglycemia ${ }^{[44]}$. Oxidation of these glycosylated membrane proteins and hyperglycemia in DM cause an increase in the production of lipid peroxides causing a hemolysis of RBC.

In this experiment, we did not measure the RBC membrane lipid peroxide levels in diabetic rabbits. However ${ }^{[45]}$ demonstrated that serum lipid peroxide level increased in diabetic rats.

It was demonstrated that $\alpha-\mathrm{MSH}$ treatment for two months after inducing DM decreased the elevated lipid peroxide level to normal level. Thus increased RBC count of $\alpha$-MSH treatment rats could be due to the lowered lipid peroxide level in RBC membrane leading to a decreased susceptibility of RBC to hemolysis ${ }^{[45]}$. Since nonenzymatic glycosylations of membrane proteins correlate with hyperglycemia ${ }^{[47]}$. However, more studies by measuring the RBC fragility and serum folic acid, iron, cobalt, vitamin B12 and calcium levels are needed to demonstrate the exact mechanism of action of $\alpha-\mathrm{MSH}$ on increased RBC count of diabetic rats.

Neutrophils ingest and kill bacteria and have been called the body's first line of defense against bacterial infections. It has been suggested that the body's defense mechanism against infections was disturbed due to the disturbed neutrophil function in diabetes ${ }^{[47]}$. In this experiment, we demonstrated that $\alpha$-MSH treatment increased the lowered neutrophil percentage of WBC $(36 \pm 3.9 \%)$ compared to control level $(32 \pm 3.7 \%)$. This result indicated that $\alpha-\mathrm{MSH}$ treatment might also increase the defense mechanism of the body against infections in diabetic rats.

Alloxan-induced diabetes increased the heart rate while $\alpha$-MSH treatment decreased it to control level. The increased heart rate in diabetic rats was probably due to the increased sympathetic output produced by diabetes-induced anemia. Theganglionic blocker hexamethonium and the non-selective muscarinic receptor blocker atropine indicating that its heart ratereducing effect occurred by activating cholinergic mechanisms antagonized the effect of the $\alpha$-MSH. In the present study, it was found that the heart rate decreased and also RBC count increased to control level in $\alpha$-MSH treated rats. Therefore, decreased heart rate could also be due to a normalized RBC count in these rats.

\section{CONCLUSION}

It is concluded that treatment ( $\alpha$-MSH) might decrease the diabetes-induced disturbances of heart rate and some hematological parameters of alloxan-induced diabetic rats.

\section{REFERENCES}

1. Bell, G.I. and K.S. Polonsky, 2001. Diabetes mellitus and genetically programmed defects in beta-cell function. Nature, 414: 788-791.

2. Tich, R. and H. McDevit, 1996. Insulin dependent diabetes mellitus. Cell, 85: 291-297.

3. Zimmet, P., K.G. Alberti and J. Shaw, 2001.Global and societal implications of diabetes epidemic. Nature, 414: 782-787.

4. Klip, A., A. Marette, D. Dimitrakouids, T. Ramlal, Shizq and M. Varnic, 1992. Effect of diabetes on glucoregulation. From glucose transports to glucose metabolism in vivo. Diabetes Care, 15: 1747-1766.

5. Taskinen, M.R., S. Lahdenpera and M. Syvanne, 1996. New insights into lipid metabolism in noninsulin-dependent diabetes mellitus. Ann. Med., 28: 335-340.

6. Vlassara, H., M. Brownlee and A. Cerami, 1984. Accumulation of diabetic rat peripheral nerve myelin by macrophages increases with the presence of advanced glycosylation end products. J. Exp. Med., 160: 197-207. 
7. Yabe-Nishimura, C., 1998. Aldosereductase in glucose toxicity: a potential target for the prevention of diabetic complication. Pharmacol. Rev., 50: 21-33.

8. Brownle, M., 2001. Biochemistry and molecular cell biology of diabetic complications. Nature, 414: 813-820.

9. Saks, D.B., 1997. Implication of the revised criteria for diagnosis and classification of diabetes mellitus. Clin.Chem., 43: 2230-2233.

10. Palmieri,V., J.N. Bella, D.K. Arentt, J.E. Liu, A. Oberman and M.Y Schuck, 2001. Effect of type II diabetes mellitus on left ventricular geometry and systolic function in hypertensive subjects; Hypertension genetic Epidemiology network (Hyper GEN) Study; Circulation (online) 103: 102107.

11. Yenigum, M., 1997. Cardiovascular diabetes. Istanbul University printing house, Istanbul, Turkey, 43: 2230-2233.

12. Garcia, L.J., L. Hamamura, R.H. Migliorini and M.P. Leite, 1973. Experimental diabetes and inflammatory reactions in the rat. Agents Actions, 3: 380-381.

13. Garcia, L.J. and S.P. Farsky, 1993. Hormonal control of inflam- matory response. Mediators of Inflammation, 2: 181-198.

14. Rayfield, E.J., M.J. Ault, G.T. Keusch, M.J. Brothers, C. Nechemias and H. Smith, 1982. Infection and. diabetes: The case for glucose control. Am. J. Med., 72: 439-450.

15. Taylor, A.W., J.W. Streilein and S.W. Cousins, 1994. Alpha-melanocyte-stimulating hormone suppresses antigen-stimulated $\mathrm{T}$ cell production of gamma-interferon. Neuroimmunomodulation, 1: 188-94.

16. Luger, T.A., T. scholzen and S. Grabbe, 1997. J. Investing. Dermatol. Symp. Proc., 2: 87-931.

17. Mugridge, K.G., M. Perretti, P. Ghiara and L. Parente, 1991. Alpha-melanocyte-stimulating hormone reduces interleukin-1 beta effects on rat stomach preparations possibly though interference with a type 1 receptor. Euro. J. Pharmacol., 4: 151155.

18. Dirk, H., G. Versteeg, P.V. Bergen, A.H. Adan and D.J. De Wildt, 1998. Melanocortins and cardiovascular regulation. Euro. J. Pharm., 360: 114.

19. Sarker, A., Y. Sreenivasan and S.K. Manna, 2003. Alpha-melanocyte-stimulating hormone inhibits lipopolysaccharide-induced biological responses by down regulating CD14 from macrophages. FEBS Lett., 23: 286-294.

20. Nilum, R., B. Giovanni, B. Dennic, S. Sarita and P. Anna, 2003.MSH modulates local and circulating Tumor Necrosis Factor in Experimental brain inflammation. Endocrinology, 144: 360-370.
21. Luger, T.A., T. Scholzen, T. Brzoka, E. Becher, A. Slominske and R. Paus, 1998. Cutaneous immunomodulation and coordination of skin stress responses by alpha-melanocyte-stimulating hormone. Ann. N.Y. Acad. Sci., 1: 840: 381-394.

22. Eves, P., J. Haycock, C. Layton, M. Wagner and H. Kemp, 2003. Anti-inflammatory and anti-invasive of alpha-melanocyte-stimulating hormone. Br. J. Cancer, 89: 2004-2015.

23. Oktar, B.K. and I. Alican, 2002. Modulation of the peripheral and central inflammatory responses by alpha-melanocyte-stimulating hormone. Curr. Protein Pept. Sci., 3: 623-628.

24. Horst, L.F., S. Rudiger, K. Werner, G.P. McGreogor, B. Ulrich and B. Jan, 2001. The melanocortin melanocyte-stimulating hormone/ Adrenocorticotropin 4-10 decreases body fat in humans. Clin. Endo. Metab., 86: 1144-1148.

25. Leiba, H., N.B. Garty, J. Schmidt-Sole, O. Piterman, A. Azrad and Y. Salomon, 1990 The melanocortin receptor in rat lacrimal gland; a model system for the study of MSH (melanocytestimulating hormone) as a potential. Eur. J. Pharmacol., 181: 71-82.

26. Miller, R., T. Toneff, D. Nishuvardhan, M.C. Beinfeld and V.Y. HooK, 2003. Obliteration of Alpha- melanocyte-stimulating hormone derived from POMC in pituitary and brains of PC2deficient mice. Neurochemistry, 86: 556-563.

27. Fortes, Z.B., S.P. Farsky, M.A. Oliveira and J. Garcia-Leme, 1991. Direct vital microscopic study of defective leukocyte-endothelial interaction in diabetes mellitus. Diabetes, 40: 1267-1273.

28. Araki-Sasak R, Sumida Y. Katsuki, A. Hayash, M. Ideno, T. Tanaka, M. Furuta, K. Nakatani, Y. Hori, Y. Yano and Y. Adachi 2002. Effect of alpha melanocyte-stimulating hormone on glucose transport in rat adipocyte. Tsu, Mie, 514-8507, Japan.

29. Lishner, M., S. Akselrod, V.M. Avi, O. Oz, M. Divon and M. Ravid, 1987. Spectral analysis of heart rate fluctuation: a non-invasive, sensitive method for early diagnosis of autonomic neuropathy in diabetes mellitus. J. Auton. Nerv. Syst., 19: 119-125.

30. Tamate, H.B. and T. Takeuchi, 1984 Action of the e locus of mice in the response of phaeomelanic hair follicles to -melanocyte-stimulating hormone in vitro. Science, 224: 1241-1242.

31. Huszar, D., C.A. Lynch, V. Fairchild-Huntress, J.H. Dunmore, Q. Fang, L.R. Berkemeier, W. Gu, R.A. Kesterson, B.A. Boston, R.D. Cone, F.J. Smith, L.A. Campfield, P. Burn and F. Lee, 1997 Targeted disruption of the melanocortin-4 receptor results in obesity in mice. Cell, 88:131-141. Kennedy, L. and J.W. Baynes, 1984. Nonenzymatic glycosilation and the chronic complications of diabetes: An Overview. Diabetologia, 24: 93-98. 
32. Slominski, A., J. Wortsman, T.A. Luger, R. Paus and S.G. Solomon, 2000 Corticotropin releasing hormone and proopiomelanocortin involvement in the cutaneous response to stress. Physiol. Rev., 80: 979-1020.

33. Lipton, J.M. and A. Catania, 1998 Mechanisms of anti-inflammatory action of the neuroimmunomodulatory peptide-MSH. Ann. N.Y. Acad. Sci., 840: 373-380.

34. Luger, T.A. and M. Bohm, 2004. Alphamelanocyte-stimulating hormone. Its significance for dermatology. Hautarzt, 55: 436-445.

35. Ceriani, G., A. Macaluso, A. Catania and J.M. Lipton, 1994 Central neurogenic anti-inflammatory action of -MSH: modulation of peripheral inflammation induced by cytokines and other mediators of inflammation. Neuroendocrinology, 59: 138-143.

36. Chiao, H., Y. Kohda, P. McLeroy, L. Craig, I. Housini and R.A. Star, 1997 -Melanocytestimulating hormone protects against renal injury after ischemia in mice and rats. J. Clin. Invest., 99: 1165-117.

37. Chiao, H., S. Foster, R. Thomas, J. Lipton and R.A. Star, 1996 -Melanocyte-stimulating hormone reduces endotoxin-induced liver inflammation. J. Clin. Invest., 97: 2038-2044.

38. Catania, A., N. Rajora, F. Capsoni, F. Minonzio, R.A. Star and J.M. Lipton, 1996 The neuropeptide -MSH has specific receptors on neutrophils and reduces chemotaxis in vitro. Peptides, 17: 675-679.

39. Grabbe, S., R.S. Bhardwaj, K. Mahnke, M.M. Simon, T. Schwarz and T.A. Luger, 1996 Melanocyte-stimulating hormone induces haptenspecific tolerance in mice. J. Immunol., 156: 473-47.
40. Cone, R.D., D. Lu, S. Koppula, D.I. Vage, H. Klungland, B. Boston, W. Chen, Orth, C. Pouton and R.A. Kesterson, 1996 The melanocortin receptors: agonists, antagonists and the hormonal control of pigmentation. Recent Prog. Horm. Res., 51: 287-317.

41. Bhardwaj, R., E. Becher, K. Mahnke, M. Hartmeyer, T. Schwarz, T. Scholzen and T.A. Luger, 1997 Evidence for the differential expression of the functional -melanocytestimulating hormone receptor $\mathrm{MC}-1$ on human monocytes. J. Immunol., 158: 3378-3384.

42. Rajora, N., G. Ceriani, A. Catania, R.A. Star, M.T. Murphy and J.M. Lipton, 1996 MSH production, receptors and influence on neopterin in a human monocyte/macrophage cell line. J. Leukoc. Biol., 59: 248-253.

43. Becher, E., K. Mahnke, T. Brzoska, D-H. Kalden, S. Grabbe and T.A. Luger, 1999 Human peripheral blood-derived dendritic cells express functional melanocortin receptor MC-1R. Ann. N.Y. Acad. Sci., 885: 188-195.

44. Kennedy, L. and J.W. Baynes, 1984. Nonenzymatic glycosilation and the chronic complications of diabetes: An overview. Diabetologia, 24: 93-98.

45. Meral, I., Z. Yener, T. Kahraman and N, Mert, 2001. Effect of glucose concentration, lipid peroxidation, antioxidant defense system and liver damage in experimentally-induced diabetic rabbits. J. Vet. Med.A., 48: 593-599.

46. Ganong, W., 1991. F: Review of medical physiology. 15th Edn. Lange Medical Publications, Connecticut, USA.

47. Yenigun, M., 1997. Cardiovascular Diabetes. Istanbul University Printing House, Istanbul, Turkey. 